\title{
AS MUDANÇAS DO PROCESSO CIVIL E SUAS DIRETRIZES ATUAIS
}

\author{
Alysson Leandro Mascaro \\ Doutorando em Filosofia do Direito na Faculdade de \\ Direito da Universidade de São Paulo. \\ Professor da Faculdade de Direito da Universidade Mackenzie
}

\begin{abstract}
Resumo:
As mudanças do processo civil na década de 1990 possuem características e razões que as situam num quadro maior de mudança social. Se por um lado há uma crescente maioria entre os juristas no sentido de apoio a tais reformas processuais, por outro lado há falhas graves não-observadas nestas mudanças, principalmente no tocante às garantias democráticas a um acesso social à Justiça.
\end{abstract}

\begin{abstract}
:
The changes of the civil process in the decade of 1990 possess features and reasons that point out them in a bigger picture of social change. If in a hand it has an increasing majority enters the jurists in the direction of support such procedural reforms, on the other hand it has not observed serious defects in these changes, mainly in the concerning to the democratic guarantees to a social access to Justice.
\end{abstract}

Unitermos: Ciência Processual brasileira; Processo Civil; reformas processuais; garantias democráticas.

Não nos enganemos imaginando viver num momento de culminâncias intelectuais de nossa Ciência Processual brasileira. A massiva formulação de novos institutos, de mudanças legislativas e de inovações processualísticas não lograram construir uma Ciência Processual nova nem tampouco fizeram por expurgar um passado formalista, classista e elitista de nosso processo. Este ciclo de mudanças pelo qual vem passando o Processo Civil brasileiro não é um fenômeno nem meramente academicista nem tampouco aleatório, gratuito ou descoordenado: há um norte bem claro nas propostas e nas alterações das leis processuais brasileiras, na visão nova que se vai 
formando a respeito do Poder Judiciário e do papel dos juízes, e, no fundo, há uma linha mestra, bem clara, a respeito do que se espera do Direito numa sociedade como a brasileira.

Em geral as reflexões sobre as reformas processuais brasileiras partem de constatações meramente formais: expõem-se os institutos dos diversos códigos processuais que foram vigentes no País - desde as Ordenações, passando pelos antigos códigos estaduais, os de processo de 1939, 1973 e mostrando como as reformas atuais oferecem novidade em face de um entulho processual histórico que, em muitos casos, vêm do Portugal medieval.

No entanto, esta reflexão a respeito das mudanças do processo brasileiro é falha. Sua maior carência reside no fato de que o processo civil, em quinhentos anos de história de Brasil oficial, quase nunca foi algo vivido ou saído da experiência do povo brasileiro, de suas necessidades, demandas ou buscas de Justiça, mas sim foi uma soma de institutos importados, segundo necessidades estrangeiras e lógicas diversas, para uma realidade nacional cujos pressupostos, no mais das vezes, eram totalmente diferentes dos estrangeiros. Assim, foi-se criando, na realidade brasileira, uma conjunção de interesses exploratórios e predadores, econômicos, políticos e sociais, com uma legitimação em estruturas institucionais jurídicas e processuais aparentemente legítimas, porque validadas por construções com forma processual e juridica. O problema brasileiro com o Direito, no entanto, sempre foi outro.

Quando fazemos a pressuposição de que o Direito brasileiro sempre foi uma estrutura técnica ẹ formal a serviço somente dos seus conteúdos legais, esquecemonos do fundamental: na maior parte da história do Brasil, as leis e o Direito foram meros referenciais, inaplicados e ineficazes, vinculados aos poderes econômicos, políticos e sociais existentes. Durante muito tempo nunca houve instituição judiciária nem tampouco regra processual, por exemplo, que tenha feito a disciplina e o controle do coronelismo, da corrupção generalizada do País, da truculência do poder econômico e da violência física pelos rincões de nossas terras, de tal modo que as Ordenações do Reino e outras instituições judiciais em face de casos em que os grandes poderes estavam em jogo, sempre foram reduzidas a mera fantasia judiciária.

Ocorre, no entanto, que nos tempos modernos, numa sociedade cada vez mais de massas, cujo único controle do povo e dos interesses se faz por meio da burocracia - já que resta impossível controlar pelo dinheiro ou pela violência todas as demandas e os conflitos que passam pelo Poder Judiciário - a forma de controle social muda, e muda também o interesse no Direito Processual. Durante muitos séculos, a 
forma do Direito Processual muito pouco importou, porque muito pequena era sua efetividade e sua força disciplinadora. Os poderes, quaisquer que fossem, passavam por cima de qualquer instituição. No século presente, no entanto, e na sua última metade, em específico, a forma de controle e opressão passou a ser, antes que fora da legalidade, realizada de dentro dela. Por isso, o processo civil toma uma importância institucional antes não havida, e também por isso a sua necessidade constante de adaptação a cada nova mudança das demandas econômicas, políticas e sociais.

Em épocas de Ditadura, o processo civil tinha a lógica da segurança. Quanto mais tempo demorasse o feito, quanto mais controle do fluxo do processo, assim mais condições de controle social havia para o Direito. Por conta disso, o Código, de 1973, feito pelo ministro dos militares, professor Alfredo Buzaid, não via dificuldades na demora do processo nem no acúmulo de oportunidades recursais para a apreciação dos vários graus do Poder Judiciário, porque isto, no fundo, representava um controle contínuo das meras decisões. A grande preocupação do Código, de 1973, bem como dos anteriores, nunca foi com a Justiça processual, mas sim com a segurança. Neste patamar é que se assentam os interesses com o processo civil em grande parte do século XX no Brasil.

Na década de 80, com a redemocratização brasileira e o fortalecimento - ainda que incipiente em muitas vezes - dos grupos sociais organizados, o processo civil com o único objetivo de controle social torna-se anacrônico, cumulando-se a isto a sua incapacidade de resposta às demandas econômicas, cada vez mais intensas por parte dos grupos econômicos. A pressão organizada de determinados setores, e o refluxo natural de décadas de Ditadura militar, produziram no Processo Civil brasileiro uma contínua politização dos conflitos, tornando os objetivos processuais muito mais políticos, coletivos e sociais que propriamente voltados à segurança processual. Podese dizer, mesmo, que a falta de preocupação atual com o controle rígido das etapas processuais teve sua batalha vencida na década de 80 , não agora.

As ações de caráter coletivo - Ação Civil Pública, Ação Popular -, os códigos de direitos sociais - Código de Defesa do Consumidor, Estatuto da Criança e do Adolescente -, são todos institutos exemplares desta lógica integradora do processo civil, não mais preocupada apenas com a segurança processual.

No entanto, o influxo democratizador da década de 80 sofre um revés institucional dramático na década de 90 . Se já a preocupação com a mera segurança processual estava vencida - e, vale dizer, foi nesta etapa que se venceu a disputa contra a idéia de um processo civil arcaico, meramente formal, instalado no conflito atomizado 
entre autor e réu -, a década de 90 representou para o processo civil a dilaceração das salvaguardas institucionais, somada à desconstrução da lógica politizadora do conflito jurídico. Enquanto a preocupação processual na década de 80 era com a "molecularização" dos conflitos, rompendo a sua história de "atomização" anterior, a preocupação atual do processo civil é em relação à rapidez processual. O processo efetivo, muito mais do que o processo justo, é o elemento de importância para as reformas processuais da década de 90 .

O discurso da efetividade processual esteve longamente em gestação. Já se o vê explicitamente no desenvolvimento do conjunto da obra de Mauro Cappelletti, que pretende harmonizar o processo numa sociedade cada vez mais rápida, necessitada de novos paradigmas jurídicos e judiciários, em que o desenvolvimento econômico é muito mais estruturado em torno da eficiência que propriamente da segurança. A resposta de Cappelletti às necessidades processuais é uma resposta global, para uma sociedade globalizada. Por isso investiga, na sociedade norte-americana, institutos processuais que irão ser aplicados na Itália e tomados como receituário para os problemas institucionais de países como o Brasil. Por conta disso, toda a especificidade e os dilemas da sociedade brasileira são olvidados em face das respostas novidadeiras que necessitam de uma globalização, porque os interessados maiores nestas respostas são sim globalizados - os interessados na dinâmica econômica da sociedade.

Pode-se dizer com folga, as reformas apregoadas por Cappelletti, e assentadas no Brasil na década de 90 , vêm responder aos ditames de setores que pretendem um processo efetivo e igual internacionalmente, ao contrário de demandas específicas por Justiça nacional. Os únicos setores com atuação global e necessitados de resposta processual em tal sentido são os setores econômicos, já que as demandas nacionais brasileiras, de libertação da opressão, da ilegalidade, contra a debilidade institucional do Poder Judiciário, contra sua corrupção e contra sua má formação, apenas técnica e desligada dos problemas sociais, todas estas preocupações não entram no quadro das demandas empresariais transnacionais contemporâneas.

Some-se a isso o fato de que, no caso específico brasileiro, uma década de avanço institucional processual - a década de 80 - começou a representar um significativo quadro teórico e às vezes prático de conquistas sociais. A proliferação dos Procons, grupos de defesa do consumidor, do menor, do meio ambiente, do saneamento básico, ações contra prefeitos, governadores, maior poder ao Ministério Público, tudo isto representa um patamar em geral causador de atritos com uma lógica econômica de lucros máximos. A conservadorização do Poder Judiciário na década de 
90 - acabando-se, por exemplo, com movimentos como o do Direito Alternativo - é um sinal indicativo claro de que as reformas processuais, ao contrário do que acontecia na década de 80 , quando se deu no campo do Poder Legislativo, por meio de leis que poderiam cada vez mais ser aprofundadas, passaram a ser, na década de 90 , concentradas no próprio Poder Judiciário, já mais conservadorizado, aumentando o poder dos juízes e, com isso, esvaziando as eventuais conquistas legislativas socializantes com a aposta no conservadorismo judiciário. A bandeira do poder aos juízes, em última análise, na década de 90 , quer dizer só num certo sentido rapidez processual, porque em seu fundo está a idéia de freio às conquistas sociais que possam surgir legislativamente.

Os juízes para a democracia ou alternativos, subindo aos tribunais, tornando-se mais velhos e cada vez menos arrojados, já não representam mais medo do que qualquer conquista legislativa, cuja capacidade democrática é hipoteticamente maior - uma vez originária do voto popular - do que o Poder Judiciário, principalmente o dos tribunais, controlados corporativamente, e cuja seleção nunca é popular, mas sempre política, abrindo espaço para o crivo ideológico. $\mathrm{O}$ fortalecimento processual do Supremo Tribunal Federal, controlado diretamente pelo Governo, é um exemplo de domínio por meio de transformações processuais. Não é outra a fundamental preocupação que orienta a renitente idéia da Súmula Vinculante.

Podem ser visualizados três paradigmas distintos do Processo Civil brasileiro nos últimos tempos: o do processo civil como controle ou segurança, cujo exemplo maior é o Código Buzaid, na década de 70, o processo civil como coletivização dos conflitos, na década de 80 , e o processo civil como efetividade ou rapidez, com concentração nas mãos dos juízes, na década de 90 .

Se verificarmos cada uma das reformas processuais em voga na década de 90 , veremos a tendência, sempre explícita, à concentração de poderes nas mãos dos juizes, à rapidez processual, o que representa o corte das possibilidades recursais e das garantias dos que se utilizam do Poder Judiciário, além de uma tendência sempre presente à despolitização e à desestatização da Justiça. Três exemplos são significativos deste paradigma contemporâneo do processo civil: os Juizados Especiais, a Lei de Arbitragem e as Reformas Recursais. Neles debrucemo-nos um pouco mais em especial.

Nas últimas décadas, em especial nesta, vem-se ouvindo o discurso de que o autor e o réu, no processo, são consumidores de Justiça. Excetuando-se os bemintencionados que tencionam prestar serviços judiciários com a qualidade de empresa que se pauta, segundo os direitos do consumidor e não com a lógica de uma auto- 
suficiência estatal, é reveladora tal idéia de processo e de suas partes. A cidadania, palavra de ordem nas elaborações de metas para a democratização do processo e da reorganização da capacidade de demanda dos grupos conflitivos, é deixada de lado em face de um elemento meramente econômico, empresarial, como se o Poder Judiciário, ao contrário de arena de afirmação dos direitos e da dignidade humana, se restringisse à mera condição de prestador de serviços judiciários. Tal lógica, e a idéia de que o Poder Judiciário não pode se contrapor às demandas econômicas nacionais - as abomináveis idéias de que a demora do Poder Judiciário causa um aumento do CustoBrasil -, fazem com que o processo civil não tenha o escopo de garantir direitos, mas sim o mero acesso à Justiça.

Quando se diz que se quer o acesso à ordem jurídica justa, isto no fundo parece se confundir com a própria idéia de acesso ao Poder Judiciário, já que teoricamente ele faria sinônimo com Justiça em sociedades ditas democráticas. Vale dizer, o objetivo contemporâneo das reformas processuais, muito menos que com a Justiça, é com o mero acesso, reduzindo ơ Poder Judiciário a mero prestador de serviços jurídicos, atrelando a este serviço a expectativa de eficiência, como uma espécie de fast-food de respostas judiciais. Por conta disso é tão-natural à Ciência Processual contemporânea a desvinculação entre Direito concreto ou substancial e Direito processual ou adjetivo. O escopo do processo é tão-somente o acesso à ordem jurídica, não às garantias últimas de Direito subjetivo que estão na base originária que dá razão de ser ao processo.

As reformas dos recursos são exemplares da importância que se dá apenas ao caráter da rapidez processual. A readequação do instituto do agravo demonstra tal expectativa em dificultar o prolongamento da demanda judicial. A ação monitória, a presunção de veracidade do título como base para a decisão do juiz, chega quase que à beira da idéia de que se precisa condenar para depois ouvir partes, numa inversão do ônus da prova que vem se demonstrando, nos últimos anos, instrumento hábil - a ação monitória - para as instituições bancárias e seus interesses. Esta busca de rapidez, ainda, leva à necessidade de busca de respostas judiciais cada vez mais céleres descortinando daí a tutela antecipada, disputando espaço nos institutos jurídicos processuais com a medida cautelar, tendo que se desdobrar a doutrina para dar estatutos próprios a cada qual delas.

Num outro caso a questão da efetividade e da rapidez processual se exacerba: os Juizados Especiais. A Lei n. 9.099/95, saída da previsão do art. 98 da Constituição Federal, de 1988, em grande parte deturpou o sentido originário da previsão 
constitucional. Se o constituinte previa uma nova forma de resolução dos conflitos, mais participativa e popular, a Lei n. 9.099 previu, na verdade, uma possibilidade de desafogo das demandas judiciais, criando Justiça rápida para conflitos de baixo valor. A estrutura toda dos Juizados Especiais é exemplar desta característica: não há grande preocupação com o Direito recursal das partes, já que se extingue a possibilidade de apreciação da sentença pelos Tribunais.

A oralidade, princípio que marca a rapidez processual, é tipicamente usada nos Juizados Especiais por conta de uma diferença que o processo civil começa a tornar banal, que é o da qualidade econômica da causa. Com a aceitação do princípio da diferença econômica das causas quer-se dizer que o Direito pode aceitar regras rápidas e despreocupadas para causas de baixo valor econômico, enquanto resguarda as instituições, os operadores jurídicos e os custos do Poder Judiciário para causas de maior valor econômico.

Ao invés da diferença de tipos de ação, os Juizados Especiais incorporam uma diferença substancial antes desta: a relevância econômica da demanda. Tal diferenciação começa a criar, na mentalidade jurídica nacional, a idéia de justiças diferentes para partes diferentes, ricas com mais acesso à Justiça, pobres tentadas à rapidez, mesmo que esta represente menor qualidade da resposta judicial, já que nem a figura do juiz preside todos os procedimentos do processo nos Juizados Especiais.

Cabe ainda a reflexão, esta explícita na sua intencionalidade, de um terceiro instituto vindo no bojo das reformas processuais da década de 90, a Lei de Arbitragem. Este instituto, previsto na Lei n. 9.307/96, dita Lei Marco Maciel, é justificado pela incapacidade do Poder Judiciário e do aparelho estatal em responder eficientemente às demandas econômicas da atualidade. $\mathrm{O}$ instituto da arbitragem, historicamente previsto no Direito brasileiro, foi reabilitado de seu esquecimento - os doutrinadores sempre expuseram seu temor em face do instituto, que não-permitia apreciação judicial posterior do conflito -, e ao mesmo tempo foi louvado em suas qualidades, a de rapidez e a de diferenciação da lógica legalista que preside o Poder Judiciário e suas decisões. Vale dizer, um instituto apropriado às necessidades satisfativas econômicas, que não vêem nas leis regras acordantes com seus interesses. Em especial as últimas décadas vêm instituindo conjuntos de regras e responsabilidades custosos para o desenvolvimento econômico de lucro total, e a desconstituição das garantias sociais e dos direitos em geral suscita polêmicas se trabalhada dentro do Poder Legislativo, de tal modo que a Arbitragem, em seu trabalho específico de cada caso, faz com melhor resultado, e sem polêmica organizada, aquilo que, no que tange às leis, 
causaria exposição pública desvantajosa. Quebrar as legislações sociais é um . extremamente oneroso; julgar conflitos sem lei, como no caso da Lei de Arbitragem, parece ser a flexibilização ideal sem custos políticos.

A tentativa de privatização do espaço público tem, na Lei de Arbitragem, um dos seus mais acabados exemplos. A participação da cidadania passa a se excluir dos interesses que movimentam as alterações das reformas processuais brasileiras contemporâneas. A efetividade, a rapidez, e mesmo a liberdade das amarras do sistema legalista, são todas metas as mais apropriadas possíveis para um sistema de resolução , dos conflitos do agrado dos poderes econômicos e da sua inabilidade e desinteresse em operar na esfera do espaço público nacional, privatizando as demandas e, muitas vezes, levando-as a organismos de arbitragem internacionais.

Legalidade, eficiência e Justiça: as demandas contemporâneas do processo e do Direito.

A grande batalha do Processo Civil brasileiro está ainda a ser vencida, em quinhentos anos de história oficial: até os dias de hoje, instituições judiciárias e processo formal representaram em grande parte ficções justificadoras das opressões, tendo em vista que se conjugaram sempre com as mais nefastas formas de domínio econômico, político, social, com as formas mais primitivas de coronelismo e feudalismo até com as últimas e recentes utilizações do Poder Judiciário pelas redes de corrup̧̧ão, pelo narcotráfico e outras estruturas ilegais ou extralegais.

O grande problema processual brasileiro - como de resto de todos os países explorados e que até os dias de hoje não tomaram em suas mãos o controle estatal sobre os poderes antigos ou novos de subjugação - é o fato de que instituição e previsão processual são instrumentos verificados e utilizados não contra a ilegalidade, mas em proveito dela na medida em que as instituições são, às vezes, facilmente manipuláveis.

As modernas contribuições da filosofia e da ciência política, no século $\mathrm{XX}$, vêm nos ensinar que a dificuldade jurídica básica, em países como o Brasil, reside no fato da existência de um sistema legal que se aplica apenas ou-só formalmente ou então apenas contra as causas que não envolvem risco aos grandes poderes políticoeconômicos, já que as instituições do sistema estatal-jurídico são criadas e vivenciam em simbiose com os poderes tradicionais, muitos extralegais, juntos dos poderes econômicos e até mafiosos atuais, corrompidos e corruptores. O Processo Civil brasileiro, num Estado que perde força, necessita, antes de tudo, de reforço na sua 
institucionalização. Urge ainda, em quinhentos anos de Brasil oficial, a vitória total de um Estado de Direito.

Ao lado desta preocupação fundamental, numa sociedade contemporânea cada vez mais integrada fora dos limites do Estado e da nação e cada vez mais dependente da temporalidade e da rapidez da resposta judicial às demandas, a efetividade se soma como elemento de grande importância à reflexão acerca do processo. Tal efetividade, é certo, exige grande dose de reestruturação dos próprios poderes judiciários, uma vez que a sua carência física e operativa reflete na demora da prestação jurisdicional. A efetividade maior, que é a possibilidade de acesso do Poder Judiciário ao povo, esta se faz somente com uma nova visão do processo e do Direito, visão esta coletiva, popular, que entenda as especificidades e as necessidades de um povo oprimido e que saiba trabalhar no sentido da correção das injustiças reais que se conservam no processo, uma vez que este conserva uma igualdade formal que não corresponde à desigualdade real.

A rapidez processual, por certo, é elemento fundamental da sociedade contemporânea nas suas relações econômicas e sociais; no entanto, não pode ser discurso gratuito, sob risco de se tornar autoritarismo respaldado em leis. As nações totalitárias em geral, no século XX, têm demonstrado apreço por efetividade processual no sentido de rapidez, sendo instrumento primeiro para tal objetivo o estrangulamento das possibilidades recursais e das garantias do cidadão, e a alta concentração do poder processual nas mãos dos operadores estatais. $O$ processo nazista era deveras rápido. Processo rápido nunca foi sinônimo de processo justo.

Se o institucionalismo processual é fraco num fraco Estado de Direito como o brasileiro da atualidade, e se a efetividade, dados os seus limites nas garantias fundamentais, soma-se ao projeto de transformação das instituições processuais, certamente a grande renovação do pensamento processual reside no problema da Justiça no processo. Repensar a relação jurídica processual não mais segundo uma visão primária e tradicionalista entre partes individualizadas e sempre iguais formalmente, autor e réu, mas pensar uma sociedade com conflitos ideológicos e sociais de complexidade extrema, é transformar as expectativas em relação ao processo, ao mesmo tempo em que restará imprestável a lógica institucional e formal que rege o processo dos dias atuais. As novas formas de relação jurídica, que possam dar conta de uma complexidade dos conflitos e dos interesses, numa sociedade que vive em opressão coletiva e não-só individual, exige nova racionalidade jurídica, nova compreensão do papel do jurista e do operador do Direito, e no fundo novos sonhos de Justiça. 
Realimentar estes sonhos de Justiça faz parte da gestação de um processo mais justo, que é reflexo necessário, por sua vez, de um Direito preocupado não mais como só em sua tecnicidade, mas com os caminhos e os objetivos do justo.'

São Paulo, janeiro de 2001. 